\title{
Reappraising Urban Planning and Urban Sustainability in East Africa
}

\author{
Shuaib Lwasa ${ }^{1}$ and Cecilia Kinuthia-Njenga ${ }^{2}$ \\ ${ }^{1}$ Makerere University \\ 2UNEP \\ ${ }^{1}$ Uganda \\ ${ }^{2}$ South Africa
}

\section{Introduction}

In recent times, sustainable urban development has been a major challenge confronting the African region generally. This situation is further exacerbated by Africa's rapid urbanization at an average rate of 3.3 per cent per annum between 2000-2005. A rapidly urbanizing region, projected estimates indicate that by 2025 approximately half of the African population will be urban (UN-Habitat, 2008/9). This outstanding demographic shift on the African continent, and particularly Eastern Africa, presents current and future challenges for urban and regional planning (Lwasa, 2008; Rakodi, 1997). Furthermore, according to the UN-Habitat State of the World's Cities Report, 2006/7, rapid urbanization in Africa has occurred in the absence of a stable economic base though recent economic experiences show averagely high GPD rates for various countries. With chronic poverty widely prevalent, urbanization and slum formation are inextricably linked (UN-Habitat, 2007). Compounding this situation current statistics indicate that slums grew at a rate of 4.53 per cent per annum while overall urban growth rates were 4.58 per cent in the same period (UN-Habitat, 2008/9) almost leveling the urban growth is thus synonym to slum growth.

Africa urbanism is increasingly characterized by endemic poverty levels, fragmentation of the formal economy, weak institutions, declining employment and non-existent or deteriorating service provision (Clarke, 1995; UN-Habitat, 2009). But African urbanism also presents unique positive aspects and processes of urban space definition, use and spatial development patterns in which individual ingenuity for survival innovatively utilizes urban space in a productive way. These two strands of African urbanism present opportunities but also have created daunting challenges for sustainable urban development. Sustainable urban development in Africa and East African which would ensure social service provision, sustainable economic development, housing delivery, good urban governance, guided spatial development and urban environmental management. More recently urban development is challenged by mitigation and adaptation to climate change (Lwasa, 2008; Rakodi, 1997). The urban sustainability question in East Africa will require well designed pathways for urban development. This also raises the critical question of whether existing theories, models and practices of urban development offer solutions to the development and planning needs in the African continent and Eastern Africa in particular (Lwasa, 2008; Akatch, 1995). 
This chapter critically assesses the role and impact of urban planning processes in Africa generally, and Eastern Africa in particular, with regard to addressing the scale and magnitude of current urbanization challenges. The chapter broadly outlines the global perspectives on urban planning followed by emergence and nature of urban planning in sub-Saharan Africa. An overview of urban planning instruments follows with emphasis on current approaches being applied and their possible impact addressing the daunting urbanization challenges confronting the region. The instruments are examined in context of current urban development experiences in East Africa critiquing the predominant master planning and structure planning approaches. Finally, the chapter outlines leverage points for innovative planning approaches for sustainable urban development and responsiveness to the urban realities of East Africa.

\section{Method and materials}

A compendium of studies have culminated into this synthesis of appraising urban planning in East Africa. Two extensive literature review studies have examined the experiences of planning in general and urban planning in particular conducted in respect to cities in Kenya, Uganda and Tanzania. The review was conducted between 2006 and 2009 parts of which have been published in the UN-Habitat Report on Planning for Sustainable Cities and several other papers. These studies have focused on the theoretical underpinnings of urban planning comparing the theories and models to the current urban imprint while examining the alignment between the global north models of urban development and the existential spatial structure of cities in East Africa. The Master Planning and Structure Planning approaches are examined in view of urban realities in the region. Urban development models at city-wide to neighborhood scales are also examined in the review to identify divergences and convergences of global north and global south experiences focused on East Africa, the results of which is the synthesis in this chapter. Three additional studies have been conducted in the cities of Nairobi and Kampala at various scales from neighborhood to city-wide levels delving into issues of the current urban imprint, the role of urban planning (including planning by inaction) in creating the imprint and what leverage points can be harnessed for urban planning innovation. The latter have extended debates on various substantive planning issues, which are covered in the later sections of the chapter. The three thematic studies include the Making the Edible Landscape, Urban Planning Reality Studio and the Innovative Urban Planning Project. Ranging from two to three years of study, the projects deployed multi-faceted methods including participatory learning and action, service learning methods bringing various stakeholders to working together in identifying scalable and practical solutions to locale specific urban issues. The knowledge from these studies is the basis of this synthesis of appraising urban planning approaches. The synthesis links neighborhood level experiences to city-wide realities and potentials. The systemic failures of 'traditional' planning approaches are identified which are the springboard to identifying leverage points for innovative planning that takes into account urban realities in the region.

\section{Urban planning a global perspective}

Globally urban planning can be historically traced in northern Europe before it was spread to other regions including Africa. On the advent of planning in Africa, theory and models 
for urban development were largely transferred from Europe and overlaid on African traditional systems that were arguably unprepared for the new systems of housing, standards, public services and development control procedures that were characterized by top down approaches(Smyth, 2004, Shalaby, 2003, Ndura, 2006). Planning practice remains very similar to colonial administration bent on the legal approach. Urban planning in East Africa still follows approaches and practice that respond to substantive and process theory; positive and normative theories with various planning colloquiums such as centralized versus transformational planning systems(Bennett, 2003). On the other hand are the Global South theories, models and practices with a couple documented while many remain undocumented or systematically described(Ndura, 2006). This divide provides a very good basis for our understanding in the subsequent sections of the entry points for innovation in urban planning. Based on the theories outlined, planning practice in East Africa has largely been influenced by paradigms of Master Planning, Structure Planning and currently under test in some countries of the region is innovative planning (Valk, 2002, Simpson and Chapman, 1999). These paradigms have pursued planning in different ways; functional versus territorial planning; geographical and administrative area planning and time horizon planning(Bennett, 2003).

\subsection{The dominance of the master planning approach}

In Eastern Africa, urban planning is understood to refer to physical land use planning, consisting of three key elements: first, an overall framework, usually a master plan, second, a set of planning and building standards and regulations and third, a development control system (Clarke, 1995:3). The master planning approach remains the most dominant in the region. This situation has been attributed to a large extent to the nature of professional training, which is still undertaken within a context of strong architectural and civic design traditions underpinned by the political, social and cultural values of the North (Jenkins et al, 2007; El-Shakhs, 1997). Therefore, as Shalaby (2003) aptly noted, "urban development is very much a social process constructed by planners whose orientation is shaped by global North theory and or their own experiential knowledge, which does not necessarily fit with the social problems and needs".

Master plans depicted on a map state the desired form of an urban area at a future point in time when the plan is 'realised' (UN-Habitat, 2009:60). The master planning approach has been critiqued in the planning literature, and in practice replaced by processes and urban plans that are more flexible, strategic and action oriented. According to Jenkins et al; (2007:132), some of the major criticisms of the master planning approach, include the focus on the plan as a product rather than on its effects; the stress on spatial factors and land use compared to social; economic and environment issues, the less focus on rapidly changing forces which shape urban development; the failure to recognize the significance of spontaneous settlement and the practical issues involved; the norms and standards which are global north dominated; the inadequate consideration of critical issues of financial analysis; governance, political interests and the realities of urbanizing poverty. As observed by Clarke (1995:14-15), the net effect of the inadequacies of the traditional master planning approach is that the majority of urban growth has taken place outside the planning 'rules of the game' directly contributing to social and spatial maginalization or exclusion (UN-Habitat, 2009; Jenkins et al; 2007). Although it has received critique, the approach remains particularly strong 
in majority of African countries with a general reluctance to reform the systems giving rise to organic approaches and interventions by the various stakeholders in the cities.

In a similar vein the much promoted flexible instruments including the 'Structure Planning approach has also faced problems and critique. Structure planning addresses a broader range of social, economic and physical development thereby enabling a more flexible base for the preparation of local plans (Jenkins et al; 2007; Akatch, 1995). On the other hand, action planning is an implementation-oriented approach to solving problems at a local level with community participation as a key to success and using local adaptation of experiences from other contexts effectively translating to a "learning by doing" approach (Clarke, 1995; Nigel, 1998; Hopkins, 2001). Despite recognizing the stakeholders, in principle enabling participation and flexibility around changing envisaged future structures of the city or neighborhood, this approach has not substantively addressed the issues around governance political interests and multi-stakeholder engagement. Therefore, part of the failure of urban planning instruments in Africa generally is attributed to their conceptual and contextual weaknesses to align with African environment and difficulties arising from the complex and dynamic interplay between global, national and political economy in which urban planning has to be undertaken in the region (Akatch, 1995; Mabogunje, 1990). Consequently, an important lesson learnt from the failure of the approaches in Africa generally is the inherent danger of transplanting planning systems and approaches from one context to another given the highly varied nature of urban societies globally. In addition, urban planning is still perceived as a specialist and technical activity, the exclusive preserve of skilled and commonly foreign trained segment of the professionals and or foreign consultant (Akatch, 1995; UN-Habitat, 2009).

Despite the rich theory and approaches, the question is whether the outputs and means of achieving elaborated plans have translated into spatial-social changes in cities of East Africa. An additional question is whether envisaged outcomes of the plans correspond or fit with the societal values, needs and aspirations? As noted by (Diaw et al., 2002), planners have been equipped with sufficient skills and knowledge necessary for responding to the planning needs but this has largely remained for plan outputs and less to implementation of the outputs. Several research, evaluation and commentaries have presented the successes and failure of planning in the Global South(Mukwaya, 2001, Goodfellow, 2010, DPU, 2004, Arimah et al., 2009). From Orangi project in Karachi to Lima and Bogota, Lagos and Nairobi, literature shows fewer successes of planning which has been largely dominated with Global North theories and models (Egbu et al., 2006). Literature shows that adapting the theories and approaches to locale specific realities has a potential for transformative urban development. From the Orangi Project for example, experiences show that local human capacities and resources can create a spin to urban development that is parallel to the topdown approaches though community participation is plagued by challenges of scalability. The inability of spatial plans to subsequently realize societal goals, to deal with housing problems, poverty, urban services, urban environment and enhancement of urban governance is evident in most of the cities of sub-Saharan Africa(Jain, 2003). While efforts and sectoral initiatives by development agencies, UN organizations spearheaded by UNHabitat, Civil Society Organizations and Governments are also yielding less than the badly needed results of planning (Jain, 2003). Planning and its outputs or outcomes in this context can then be looked at as a distinctive fusion of Global North and or Global South practices. 
Looking at these experiences, then a question can be posed as to whether global north influenced planning and practice is relevant for $21^{\text {st }}$ Century urbanization in sub-Saharan Africa? Whereas the intention is not to disqualify its relevance, it is of critical importance that entry points are identified for renewed and innovative planning that is responsive to societal needs in the context of African urbanism. The subsequent sections will endeavor to provide some pointers to this question and raise some of the much needed changes in theory, policy and practice around which planning innovations are needed.

\section{Urban planning in the Global South}

Pre-colonial settlement and urbanization is recognized in literature but in Eastern Africa, urbanization is largely viewed as part of European colonization. Urban planning processes are also inextricably linked to European town planning practices. In particular, it should be noted that British colonial rule profoundly influenced the nature of urban development in East Africa especially from the late nineteenth century until independence. As Akatch (1995:42) points out, the African region provided ideal experimental grounds for new colonial centers with urban planning processes literally exported as part of the cultural baggage of imperialism. Indeed, as aptly stated in the UN-Habitat Global Human Settlements Report, (2009:60), "frequently, these imported ideas were used for reasons of political, ethnic or racial domination and exclusion rather than in the interests of good planning systems". Thus the current planning systems and urban imprints are largely a legacy of colonial planning practice manifest in a physical sense through the segregated residential quarters (Jenkins et al; 2007).

Furthermore, there are also strong connections in terms of planning legislation, institutional structures and administrative processes (Okpala, 1987). In this regard, town planning legislation for many countries in the region, for example, Kenya, Uganda, Nigeria, Zimbabwe, Zambia has its roots directly in British town planning laws and was transported without modification to the new situation, irrespective of the different circumstances prevailing in the recipient country (Akatch, 1994). However, as Kanyeihamba (1973:243) argues, the adoption of transported legislation was a recipe for failure for a variety of reasons related to different political, cultural, social and economic conditions prevailing in the recipient countries. This situation was further compounded by the dire shortage of specialized manpower experienced during the colonial period, which still prevails to date in the region.

Following the attainment of political independence, very little attempt was made by the new African governments to change the urban functions of the towns and cities, which were inherited from colonial governments (Akatch, 1995). This notwithstanding, rapid urbanization was perhaps the most dramatic social phenomena that marked the end of the colonial era in Africa. From a situation in 1950 in which the total population was no more than 28 million, the figure had by 1984 jumped to well over 125 million (Mabogunje, 1990). Consequently, according to Jenkins et al (2007:115-117), planning activities in colonial Africa undertaken under the influence of western planning institutions left a mixed legacy comprising often contradicting processes and policies. These include a new 'tidal wave' of urban growth, exclusive land policies, a public sector expected to offer solutions to the pressures of urban growth, financial and technical capital inadequacies, segregation and social differentiation. 
Therefore, the influence of received planning concepts lingers on in East Africa and is continuously reinforced by the substantial influence of International Development Agencies, the 'donor community' and the planning doctrines of the global north (Watson, 2002). Surprisingly, post-colonial governments have tended to reinforce and entrench colonial spatial plans and land management tools, sometimes in even more rigid form than colonial governments (Njoh, 2003). The net effect has been that these urban plans remain relatively unchanged and unresponsive (UN-Habitat, 2009). Consequently, as Okpala (1990) argues "there is substantial external influence on the planning and development of the African urban system. The performance and service delivery capacities in the African region have also been hampered as a result of inadequacy in the quality and quantity of personnel.

\subsection{The interface between planning and urban development in East Africa}

There are many experiences of the interactions between planning and urban development in East Africa that are driven by current planning practice. This interface of the practice and the urban development experiences show how social and political processes have shaped urban development, contesting the principles that planners often come up with in developing planning policy. The experience is what some scholars like (Rakodi, 2001) have expressed as 'politics first' before planning can work while scholars have rechoed the gaps between the plans and urban development reality in sub-Saharan Africa (Lwasa, 2006, Koojo, 2005). The interface can be described as one engulfed in a mix of the 'traditional' planning concerns of societal values based on the substantive planning needs on one hand and the procedural equirements(Bennett, 2003, Koojo, 2005) with the later superseding the ability of plans to address the substantive needs. Thus conditions of inadequate urban infrastructure, housing, social services, space utilization or underutilization, congestion, inefficient public transport, poor environmental services and low urban economic transformation have been engulfed in a complex set of procedures that are known by few planners or urban managers and driven largely by politics. The result is a mixed type of urban development that which can be described as informal with pockets of formal areas creating a duality (Koojo, 2005, Egbu et al., 2006). Planning exists and professional planners are applauded with their persistent effort to ensure orderly and sustainable urban development but the translation of such effort to social reform and change remains a fundamental planning question because of the mismatch between the plans and urban development experiences.

\subsection{The Disjuncture between plans and urban development in sub-Saharan Africa}

Success of urban and regional planning in East Africa has become unpredictable(Egbu et al., 2006, Arimah and Adeagbo, 2000). Planned outcomes are often not achieved because cities develop as a result of millions of independent consumption and production decisions by different individuals, organizations and groups. On the other hand, many positive outcomes of planned interventions are unanticipated (Ssemambo, 2000, Mukwaya, 2005, Jain, 2003, Andersson et al., 2004). There is evidence of positive outcomes of urban planning which has largely been through piecemeal planning(UN-Habitat, 2008, Ssemambo, 2000). This has created pockets of isolated well planned, upgraded and developed neighborhoods, industrial parks and transportation corridors in East Africa. The failures of planning are attributed to many factors including; lack of municipal resources, enforcement, land issues, 
human resource adequacy and capacity but the issues of governance and institutional aspects have of recent become outstanding (Lwasa, 2006, Rakodi, 2001, Goodfellow, 2010). Yet the major 'players' in urban development who are the developers of differing categories and character have not been well linked to the values of planning and orderly development. But the other argument as put forward by (Leibowitz et al., Jain, 2003) the planning profession may not have actually embraced let alone been able to understand the values of communities and African urban populations. Evidence has also been generated around the missing link between the planning policy strategies and planning action very much shaped by the practice of development control (McGill, 1988). Debunking some of these practice frameworks is still a highly technical and major challenge, which maintains planning arguably as abstract that is largely non-responsive to social needs and change. The fundamental basis for urban and regional planning is for development to meet the needs and aspirations of the population or enable such population to creatively innovate to meet their own needs. It is important to recognize the differing needs and aspirations of a diverse society and or population with possibly locally defined values. This is where innovation in planning needs to strike and break the continued urban development trends in East Africa. There have been recent calls for sociocratic type of planning or ecological planning and with many concepts used, it is a type that assess the existing resource base of a community and or city to devise strategies for a catalytic spatial plan that would enable the population to unleash their potential. Resource here implies; social/political assets, capital assets, human assets and natural/man-made assets. Following the discourse of the major issues of planning theory, urban development and the analysis of planning successes and failures, it is necessary to turn to where planning needs to innovate. One can argue that planning in East Africa is at crossroads, calls for a type of 'new planning' that which among the most urgent issues needs to deconstruct the current urban development imprint.

\section{Towards new innovative planning approaches}

\subsection{Innovation in planning: What it is? And why?}

The concept innovation has been defined differently by different people(Bennett, 2003). This is because it has become a buzz word in quest for solutions to the unresolved questions and problems in various fields(Crossley et al., 2005). Innovating has been known in natural science and business as creating or finding something new in a particular context. This section attempts to provide an understanding of the concept of innovation as a launch pad for the subsequent sections of the chapter. In the context of this chapter, "innovation is understood as the development of systems that are 'new' in the context of planning, utilizing creativity that can be based on adapted local conditions principles and methods". This planning innovation would require debunking various aspects among which is the planning colloquium that has been followed for a long time. Such innovative planning would have to consider debunking of the 'business analogy' as observed by (McGill, 1988) in which he explains the operations of commercial businesses, their targets and means to achieve those targets. One needs to understand the process theory of business in this case commercially oriented business and the substantive issues of commercial business and the linkage between the business entities with the targeted market population. In the context of spatial planning, substantive issues are urban development sectors and so are the contemporary procedures characterized by a fusion of formal and informal processes. Planning innovation 
for better communities will have to emerge largely from sub-Saharan Africa where different actors in urban development would need a platform for exchange of ideas, knowledge and skills for developing strategies on how to ignite the much needed social change for sustainable and inclusive urban development.

\subsection{Innovative approaches}

From the onset, it is important to point out that the problems associated with planning approaches discussed above, and the changing urban and environment contexts have led to the emergence of more innovative or contemporary approaches to urban planning. In particular, various countries in Eastern Africa (Kenya, Uganda) have adopted new approaches to urban planning, which are under test. Strategic planning and sociocratic planning provide the framework for the new innovative approaches. Although these approaches are still under test, a few successes and potentially scalable innovations have emerged through learning by doing and engagement with communities around the longstanding urban problems in East Africa.

Strategic planning reflects the "process" view of planning and is characterized inter alia by cross sectoral co-ordination, financial feasibility, enabling mechanisms by the public sector to support both formal and informal private sector activities, realistic choice mechanisms and monitoring as well as evaluation (Jenkins et al; 2007; Clarke, 1995). Consequently, the emerging output is not just a physical development plan, but a set of interrelated strategies for city development including land, environmental management, infrastructure, economic opportunities, finance leading to a process of integrated urban development (Clarke, 1995).

Urban problems confronting East Africa are unique, locale specific and have led to evolution of locally responsive instruments of city-wide to neighborhood management (Akatch, 1995, Lwasa 2008, Lwasa 2011). Innovation has emerged in respect to financial mobilization, decision-making frameworks and processes as well as knowledge management for scaling of successes that would enable progression from micro-scale innovation to city-wide impacts. Planning innovation, can be based on adapted local conditions to spur local opportunities with built-in mechanisms for sustained social transformation for a livable urban environment". A key theme emerging with reference to urban planning and land use management in East Africa is the need to draw on real social, economic, cultural and political resources to promote solutions which are appropriate to context while 'best practices' from other countries may serve as inspiration to be de-contextualized from place of origin.

The new innovative urban planning approaches have differing entry points. Whereas adapted strategic planning provides city-wide or city regional frameworks, neighborhood innovations revolve around thematic and substantive planning issues of local economic opportunities, environmental management, service provision, managing utilities and promoting cultural diversity. Thus at these scales of intervention, the urban planning innovations have key elements of being strategic, flexible rather than fixed, action oriented, stakeholder or community, linked to political processes, environmentally responsive, socially inclusive, integrative in nature, focused on the outcomes of the planning process.

The urban planning innovations do not suggest models or solutions, which can be transplanted literally from one context to another, but rather offer general ideas, which can 
be considered in relation to the specific urban planning issues confronting the Eastern African region.

Therefore, in support of the UN Habitat Global Human Settlements Report, (2009), the new approaches can be grouped under the following categories as follows:

Strategic spatial planning which includes a strategic spatial planning system with long range, spatial planning frameworks and principles, and broad and conceptual spatial ideas.

Spatial planning as a tool for integrating public sector functions - this new approach focuses on decentralized solutions as well as a desire to 'join up' or integrate the functions of the public sector and inject spatial or territorial dimension into sectoral strategies. Perhaps most importantly this approach recognises that achieving environmental sustainability will require sectoral interests to work together and cut across traditional disciplinary and professional boundaries.

New approaches to land regularisation and management - Informality remains the most critical issue for urban planning in terms of regularization and management. Consequently, new regularization approaches require an attitudinal shift in government to recognize the potentially positive role of informality or 'emerging sector'; requires policies, laws and regulations, which are adapted to the dynamics of informality and requires efforts to improve the support for and legitimacy of the planning system by those involved in informality.

Participatory processes and partnerships in planning - In general, it is widely acknowledged that broad-based participation in planning can empower communities and much needed social capital leading to better design of urban projects while also allowing for participants' concerns to be incorporated into strategies. In this regard, a critical aspect would be the need to clearly redefine community roles transforming them from largely 'receivers' to major decision making stakeholders at various levels including verification of objectives, resource assessment, formulation of programmes and monitoring and evaluation (Lwasa, 2008; UN-Habitat, 2002; Fainstein, 2003). This would constitute an important first step towards responding to the failure of past development efforts that have had the unfortunate tendency of relegating the efforts of local communities to backstage in the articulation of their development needs.

Successful participation, however, remains ultimately contingent upon certain preconditions relating to the prevailing political system, the legal basis for participation and available resources and empowered local governments as well as organized communities and stakeholders. It is also important to acknowledge the important role of public-private partnerships, which have often been developed around public infrastructure especially when existing municipalities lack resources to provide the infrastructure.

Approaches promoted by international agencies - Significantly, in recent times, these forms of broader 'participatory planning' described above, have been attempted by International Development Agencies and United Nations organizations spearheaded by UN-Habitat in important initiatives including the Urban Management Programme (UMP), Sustainable Cities Programme (SCP), Local Agenda 21 (LA 21) and City Development Strategy (CDS) projects in various pilot situations although their impact still needs to be understood more specifically in context (Jenkins et al; 2007; UN-Habitat, 2006). New Urban Forms: 'New Urbanism' and the 'Compact City' - On the one hand, and at a city-wide scale, the 'compact city' approach argues for medium to high built densities, 
enabling efficient public transport and thresholds to support concentrations of economic activity, services and facilities. On the other hand, 'new urbanism' adheres to similar spatial principles, but at the scale of the local neighborhood. This position promotes a vision of cities with fine-grained mixed use, mixed housing types, compact form, an attractive public realm, pedestrian-friendly streetscapes and defined centers.

However, it should be pointed out that there is considerable overlap between these categories; some emphasize process and others outcomes and sometimes a combination (UN-Habitat, 2009). In the Eastern African context, efforts at attempting innovative participatory planning approaches have largely been spearheaded by international agencies, for example, the joint initiative of UNEP/UN-Habitat Sustainable Cities Programme in Dares-Salaam, Tanzania and the Local Agenda 21 initiative in Nakuru, Kenya. In general, the urban Environmental Planning and Management (EPM) approaches, technologies and know-how through urban local authorities based on broad-based stakeholder participatory or city consultation approaches offer innovations space.

\section{Practice and promise of innovative urban planning}

Planning practice is influenced by many factors including education and training. This section will give experiences of the practice and potentialities of scaling up the innovations. The section is based on real cases of the studies conducted in the region.

\subsection{How can planning innovate?}

There are possibly many ways through which planning innovation can be achieved and in this section of the chapter, an attempt is taken to describe some of the key areas in which innovations are required and how such innovation can be harnessed.

\subsection{Innovative planning research, moving from projects to policy and programs}

Spatial planning research has received little attention compared to development and economic planning with the two misconstrued as synonyms. Research is taken as inquest to learn what, why and how on issues of urban development. Thus even a simple field visit trip by a building inspector on a site can be monitoring but when data is collected for use later it has many research implications. Spatial planning focused research is required on substantive issues to influence outputs and outcomes of planned interventions. This has in a way directed spatial planning in terms of 'projects' and one can argue that there has been a 'projectization' of planning itself and urban development in general. The consequence is a scattering of often slightly improved neighborhoods, industrial parks and developments due to piloting while many remain in poor conditions. The key urban challenges on which planning research is useful and needed include urban livelihoods, urban environment, urban poverty, urban transportation about which knowledge is scattered, inadequate or requiring to identify alternative models for provision of services and guiding urban development. In addition there are various dynamic conditions in the urban field including governance, resource mobilization and management, the increasing role and creativity of the private-sector which despite being vibrant are also less understood from the planning point of view. 
Following the adage that "knowing a problem cause means you have solutions for it", its imperative for planning to reflect on these challenges probably with adapted or different lenses. From basic to applied research and now participatory research, these domains offer great opportunities to support planning innovation, knowledge generation and making informed planning interventions. Some of these research undertakings have been very revealing. For example whereas the planning has always grappled with the issue of 'standards' in respect to land and housing, the revelation is that possibly many people are not in position to afford such 'high standards' and coupled with other factors this influences the urban development imprint in the region(Rakodi and Lloyd-Jones, 2002, Rakodi, 1997, Rakodi, 2001). Research indicates that with this experience and projectization, a move from projects to policy thinking is necessary(McGill, 1988, Arimah and Adeagbo, 2000, LotzSisitka). A move that entails programming of urban development but which recognizes incrementalism or phasing but most important ensuring sticking to plans through the routine actions that would lead to the desired goals. Participatory research has provided some insights but maybe not answers (Lwasa and Kadilo, 2010). A triple helix model that would enable a platform of knowledge generation and exchange would be useful, one which brings together, local governments, governments on one hand, research organizations/NGO's as second category and communities as the third category, to investigate problems and search for local-based solutions within affordable ranges (Egbu et al., 2006, Higgs, 2008, Williams et al., 1999). The bringing together of various actors in urban development is now widely recognized and some of the initiatives include Urban Fora for discussion, prioritizing and directing knowledge generation for search of solutions.

A key input for planning is information on the substantive issues as well as processes (Mahavir, 2005, Lwasa, 2005) which is related to knowledge. Planning usually is preceded with collection of large data volumes, which sometimes are never processed to useful information nor getting utilized. Given the gamut of planning information needs, it means that any initiative to collect, analyze and utilize planning information could have experienced a situation of 'too much' data and 'less' utilized. This is not a surprise because planning usually projects development into the future, which may be uncertain. From social and economic surveys to spatial information on land use and other physical components, data are collected but partly analyzed. Arguably, there is an assumption that with the scale of data collection, the solutions to urban problems would be understood, explained and solutions derived. Not all the data collected by planners is actually used in a plan-making exercise. In fact "very little," a planner will discretely reply as observed by (Mahavir, 2005) that only $60 \%$ of data actually become input for plan making. The reason that planners collect so much data is a conventional approach influenced by the planning models described earlier in the chapter. Huge amounts of time and other resources are spent on collecting and analysing the same data, which in turn delays the start of the planning process, sometimes by several years Mahavir further observes. Differentiation, between essential and desirable data should provide the answer to the resources an aspect not given due attention. The key issue here is that both in terms of financial resources and time, this information takes an enormous share but if an evaluation is conducted, one wonders whether such scale of data analysis has really translated into solutions in East Africa. The innovation around planning information is likely to come from strategic determination and use of planning information given the level at which our information systems are. This would mean skimming through the available information as well as urban problems to 
identify essential data for the planning exercise. Those which if utilized would have a multiplier effect in solving other related problems. This implies dealing with the 'most important problem' that Amdam and Veggeland (1998) called the 'garbage-can-model' in which the decision making process are activated through identifying the problems, active participants and a stream of solutions by those experiencing such problems.

In practical terms, assuming urban problems of livelihoods for majority of dwellers and public transportation are serious issues in a city. If collection of data about each would have to run baselines, it would be a huge undertaking. By strategic determination and skimming, the stakeholders may view livelihoods as the most important problem and would be interested in innovatively creating employment that may translate in improved incomes, possibly having multiplier effects on housing and vibrant urban economy. This is applicable to existing cities and neighborhoods and from our research, livelihoods based strategies have a place in innovative planning(Lwasa and Kadilo, 2010). In comparison, the public transport multiplier effect may be largely in regard to the energy sector and incomes (KCC and Bank, 2000). It should be noted that the resources required for the example of studying livelihoods are likely to be far much lower than those for improving public transport. One must note however that coupling urban system components such as the two raised here would possibly produce better results and possibly in a much quicker way. However the multiplier effects should not deter investment in large infrastructure like transportation. Basing on a Kampala experience, it emerged that over $60 \%$ of the urban dwellers use either walk or cycle modes of transportation to and from their places of work. Yet resources that go into improving roads and traffic counts have been enormous. In this case innovative planning that tackles either livelihoods coupled with alternative modes of transport or one that addresses only alternative modes of transport would most likely respond to the existential needs compared to traffic counts and improvement of road infrastructure.

\subsection{Mobilizing resources for planning; From costs of plan production to societal costs}

Mobilizing resources has been touched on mainly as a big challenge in urban management(McGill, 1988). Mobilizing financial resources remains a long standing huddle in planning and urban development. Attention has been put on costs for producing plans as the case for the Master and Structure Plans. One important point is that most city or municipal scale plans have been produced with largely external funding. This is likely to continue unless there emerges an alternative strategy for mobilization of resources. There is also the much talked about local and or community level mobilization of resources which has either fallen a victim of projectization or simply not upscaled despite the good lessons(Andersson et al., 2004). There is little evidence of existing systems and initiatives for utilizing locally available resources for planning and its interventions. Yet the costs of not planning are actually those of not doing it and the planning profession cannot afford to continue this way. The societal costs are huge and if one attempted to translate them in monetary terms, it is alarming. For example in one of the study within Kampala, health related impacts of environmental burdens were monetized for the direct and indirect costs and results show that $15 \%$ of a household income is spent on defensive expenditure or costof-illness expenditure. For that neighborhood alone, a total economic value of $\$ 1.7 \mathrm{~m}$ (Lwasa et al., 2008)was calculated and if one factors in the neighborhoods with similar conditions, the cost is by no doubt high. The costs have become increasingly huge for our 
society. A possible innovation would be to use an ecological planning approach which localizes problems and solutions as well building on the existing resources available. One of the key principles of such planning is transparency in order to respond to social needs. It is probably what (Bennett, 2003) calls sociocratic planning.

\subsection{Redefining community roles}

Planning in sub Saharan Africa still remains largely technocratic, a field of practice for highly-trained and sophiscated professionals with less inclusive rules, regulations and standards(Koojo, 2005). Such planning expects adherence or non-adherence from the communities with the later followed by the 'stick' using the regulations. While it is important to have rules, regulations and standards, there is also need to recognize that such should be responsive to social needs which differ from neighborhood to another and between societies. Societal needs reflect both existential and ideals but what planning policy in East Africa responds to is largely the societal ideals. One needs to reflect on the 'societal values' theory in planning which among other tenets underpins the ideals of 'space'. In the context of urban space, one would have to muddle through differing conceptions of space depending on how it is defined and who defines it. The other issue is who determines how it would be used. Connected to the space paradox is power which is defined in governance structures(Leibowitz et al.). Existing and contemporary planning such as the rationalistic planning are silent about the roles of communities in regard to the ideals, space definition and decision making. Yet broadly speaking planning is about dialogue to enable decision making and from African perspective planning in current times is arguably about responding to needs of majority urban dwellers who have remained in deplorable conditions. In this vein, the planning has not adequately promoted decision making that is embracing communities. Often, solutions are handed down to them and this has for a long time shaped the community thinking as that of being on the receiving end. Redefining the community roles from largely receivers to major decision making stakeholders(Andersson et al., 2004) is a key innovation. This is one of the most talked about approach to 'new planning' but which has not been fully tested due to limitations regarding resources. But not testing participation has also not yielded positive results for better communities. It is important once again to note that deconstructing a neighborhood would possibly require enormous resources than constructing it with the communities progressively and incrementally.

\subsection{Innovative urban design}

As the search for inclusive urban space utilization solutions progress, innovative urban design is responding to the realities of societal needs through innovative research and knowledge generation. A mix of innovators whose desires to see a transformation of the East African cities is leading to emergence of a community of practice. For example because residential land use puts the greatest demand on urban land compared to any other use, its importance is no doubt placing it high on the planning innovation agenda. Based on a case in Kampala which was preceded by urban management policy innovation, urban design can now consider integration of urban agriculture with housing making the best use of limited space but providing housing, incomes and food while maintaining the environmental services. Making the Edible Landscape project by Kampala City Council was showcased at WUF III Vancouver and during the last session of WUF IV, Kampala was again showcased 
as one of the innovative cities by responding to the societal experiential needs (food, incomes, nutrition) through designs. Although both the results and outcomes of this innovative design are yet to be fully realized, it is a very promising innovation worth replicating and up scaling. It has further advantages of providing a basis for urban adaptive designs to climate change and variability. As contributors to GHG's and the cities vulnerability to climate change effects, adaptive urban designs that focus on plot-level hydrological, climatic and vegetative systems can have profound impact through cumulative progression of localized changes.

\subsection{Informality, formality and institutional reform}

From commentaries, research and evaluations, the informalization of urban development in East Africa has been well documented(UN-Habitat, 2008). Informality is however occurring amidst formal rules of engagement in urban development(Jain, 2003). Planning has not been spared by this informalization. There has been a good discussion of the fusion of the two seemingly different systems(Lwasa, 2006). Whereas informality has largely imitated the formal rules with adaptation, formal systems are also characterized by informality. In Kampala and Nairobi for example, the dualistic nature of urban development ((Koojo, 2005, Lwasa, 2006, Nkurunziza, 2008) describes informality of housing, infrastructure installations, services but also the development control procedure which is an important planning-policy action. The key issue regarding formality and informality concerns rules of engagement defined by institutional setup. These specify how individuals relate in urban development, their roles and responsibilities. Experience shows that institutions are characterized by three blanket levels for enforcement of the rules. The first is the official policy rules which are often well documented. The second is the unofficial policy rules that are not documented but are part of the routine policy-action of individuals in positions of public institutions. While the third are what can be considered as the official-unofficial policy rules that are neither documented but the guides of routine planning-policy action. To substantiate these rules, the discussion will focus on the last two. The unofficial policy rules are the type which individuals practice based on patronage, favors and sometimes selfish acts. Because of the risks associated with boldly identifying oneself as an agent of unofficial policy rules, this is always hidden and due to this the third category is created. The third official-unofficial policy rules are a very powerful type which lie beneath the official policy rules. They are exercised by a network of individuals in or out of organizations and often known by all staff from the top to bottom connecting to the clientele through selective information dissemination and informal channels. The rules are often described as 'usual' based on connivance, sharing information from identifying 'clients' execution of 'missions'. This has created different layers of procedures and stages in planning but also planning policy-action. Planning has not properly addressed these dynamic political and social processes of dispensation of services. The innovation in this sphere is by no doubt 'noble' and will have to involve adapting the official policy rules. The role of leadership is very significant in enabling innovation in this sphere and critical in this much desired change.

\subsection{The planning toolbox}

For long, the planning toolbox has also remained a black box in the sense that it has been so technocratic. The planning toolbox has components such as accurate data, equipment, the 
Acts, the models and principles. If unpacked, the toolbox is changing but not at a speed desirable to fit in with the strategic determination of planning information to focus on essential data as well as linking policy guides to policy-action. Contemporary planning tools are dynamic and changing very fast(Mahavir, 2005, Lwasa, 2005). In Uganda for example, the toolbox has changed but there are still many areas for improvement around which innovations can be generated. In this section the planning toolbox elements of Acts, data and equipment are the focus. Starting off with the Acts, in East Africa have not been inclusive and sensitive to the needs of Africans. In addition the code of conduct professional and ethics have not been strengthened for long until recently. For example in Uganda the revision of the Town and Country Planning Act 1964 into the new Physical Planning Bill is very laudable and provides a platform for innovation(2008). One of the many innovations in the new bill is the response to the longstanding planning question of 'planning area boundary', by including rural areas and implicitly the peri-urban, the bill provide mandate to planning authorities to prepare or cause prepare plans for areas with a potential to explode outside the official planning area boundary as local physical development plans. In Kenya the creation of the Nairobi Metropolitan Ministry in 2008 is a laudable effort in establishing formal structure to address the metropolitan growth of the city. Planning education needs to quickly embrace these new changes from the public policy domain and prepare future planners to respond within such laws. While the other two components of accurate data and equipment are some of the areas with urgent need for innovation. While working in partnership with other professions and disciplines, it is important to address the need for spatial information, techniques for plan formulation and design of planning information systems that would probably reduce the costs of planning information collection and analysis as discussed earlier. The emergence of Global Navigation Satellite Systems (GNSS), Global Positioning Systems (GPS), Geographic Information Systems (GIS), Remote Sensing with associated systems of Spatial Data Infrastructure (SDI), web-based mapping, online planning are areas worth exposing to future planners (Lwasa, 2005). These techniques and tools provide means for quick accurate information which can aid quick response to planning problems while helping in establishing planning information systems. They also provide a powerful advantage of enabling community-access to planning information, designs and neighborhood conditions that reduces the burden on the part of planning authorities.

\subsection{Planning education}

For a long time there has been an argument that planners in Africa have a theoreticalprofessional-practice foundation with a global north touch(James Otieno, 2009). This is true given the history of planning education in sub-Saharan Africa that was characterized by first level training in a different discipline before receiving training in planning at graduate level. Evidence shows that the switch to African based training and education in planning has provided the much needed human resource to confront the urban development challenge with argument that local training will enable planners to gunner experiential knowledge in terms of planning needs, problems and solutions(Diaw et al., 2002). But what is yet to be seen is the translation of this experiential training into real solutions to the local planning problems and challenges(DPU, 2004, Breidlid, 2009). One of the many attributes of this type of training is that it still largely remained shaped by planners whose skills, theory, practice and models do not properly align with the urban development pathways in East Africa. 
Thus innovation around education is necessary and such would have experiential knowledge but also solutions that are responsive to the problems of African urbanism. For example the issue of planning standards for housing (materials, sizes, plot coverage) has been discussed at different fora and international level but has not been substantively resolved nor have flexible or adaptive standards developed (Rakodi, 1997). However good practices or cases from various countries including Uganda, Tanzania have considered mixed residential with light industry to take into consideration of home-based small scale industrious activities. This is just one among the many ways in which planning education can be innovative. This innovation required in broad requires an in-depth review and reorganization of the education system.

\section{The limits of planning innovation}

It is important to emphasize that despite the promises of innovative urban planning in Eastern Africa, many of the challenges and problems remain unresolved. These will limit the possibilities for a move to renewed planning and sustainable urban development in East Africa.

One of the challenge in the region is the exponentially rising population growth and rapid urbanization in proportion to the planning response. For example, it is anticipated that the urban population in Africa will increase from 129 million in 1980 to more than 762 million in the year 2025 by which time it is estimated that over 52 per cent of the region's population will be living in towns and cities as compared with about 30 per cent of urban population recorded in the region by 1986 (Akatch, 1995:40). Whereas the growth isn't a problem in self, if compared to responses from the public and private sectors, these don't match. Thus the characterization of public responses in terms of overconcentration of resources and infrastructure in capital cities, inadequate and or defective national planning policies, lack of institutional and inter-sectoral co-ordination, ineffective development control enforcement measures and inadequate involvement of relevant stakeholders (Akatch, 1995:39; Clarke, 1995; UNCHS, 1999; UN-Habitat, 2009). Other initiatives such as the Sustainable Cities Programme and the Local Agenda 21 have inherent weaknesses that will challenge achievement of urban planning innovation. The difficulty in measuring the impact of the participatory processes, performance of local authorities, leverage of city consultations and inability of various partners to remain engaged with the same city for a long period of time have been projected as likely to maintain overambitious in nature of plans generated through city consultation (UN-Habitat, 2009). In addition, while different urban issues, political, economic and institutional systems, as well as different cultures and value systems, all shape the planning system in diverse ways, following and adhering to the normative principles will also pose some challenges.

\section{Conclusion}

This chapter set out to critically examine the role and impact of urban planning processes in Eastern Africa particularly with regard to addressing the sheer magnitude and scale of current urbanisation problems confronting the region. In setting the general context, the nature and emergence of urban planning in the region was briefly examined. In particular, it was emphasized that the evolution of urban planning in the region can be directly traced to the 
background of urbanisation in Africa, which is inextricably linked to European colonisation with the net result of there being many experiences of the interactions between global North oriented type planning and urban development experiences in sub-Saharan Africa (Lwasa, 2008; Akatch, 1995; Kessides, 2006). In addition, various urban planning instruments in subSaharan Africa were critically examined. From the onset, it was emphasized that the master plan approach remains the most dominant to date, although in recent years this particular instrument has been increasingly criticized for being complex, excessively bureaucratic, time consuming, non participatory and too static in nature. The potential offered by new urban approaches was briefly discussed including the key elements underpinning them although it was emphasized that these approaches did not suggest models or solutions, which could be literally transplanted from one context to another.

In conclusion, spatial planning in East Africa is at cross-roads and facing a huge challenge as the demographic shift creates an urbanized. Planning innovation is necessary to change the current urban development trends and imprint but such innovation will have to involve various stakeholders and in various spheres. The key spheres that could have multiplier effects include; planning practice, planning research, planning information and redefining community roles. For better communities in urban areas the response of the planning profession should address the social needs and endeavor to harness the potentials of communities based on the realities of current development. This is the key for transforming urban communities in East Africa. The time for planning innovation in East Africa is past and in this context the planning profession as well as other stakeholders should take initiative and start now because the cost of not adequately planning is so huge. However, several weaknesses of the participatory processes have been identified that create limits of new approaches to urban planning in the Eastern African region.

\section{References}

2008. The Physical Planning Bill, 2008. 31.

Akatch, S. 1995. "Evaluative Review of Urban Planning Practice and Experiences in Africa" in Mosha, A (ed). 1995. A Reappraisal of the Urban Planning Process. Nairobi: UNHabitat.

Andersson, N., Matthis, J., Paredes, S. \& Ngxowa, N. 2004. Social audit of provincial health services: Building the community voice into planning in South Africa. Journal of Interprofessional Care, 18, 381-390.

Arimah, B. C., Jensen, I., Mutizwa-Mangiza, N. D. \& Yemeru, E. A. 2009. Planning Sustainable Cities: Global Report on Human Settlements 2009. New York: UNHabitat.

Arimah, C. B. \& Adeagbo, D. 2000. Compliance with urban development and planning regulations in Ibadan, Nigeria. Habitat International 24, 279-294.

Arko-Adjei, A., Jong, J. D., Zevenbergen, J. \& Tuladhar, A. Customary Tenure Institutions and Good Governance. In: FIG, ed. International Federation of Surveyors, 2010. FIG, 17.

Bennett, R. G. 2003. Planning Theory and Power. Center for Studies of Environment and Resources, University of Bergen. 
Breidlid, A. 2009. Culture, indigenous knowledge systems and sustainable development: A critical view of education in an African context. International Journal of Educational Development, 29, 140-148.

Brockerhoff, M. P. 2000. An Urbanizing World. Population Bulletin, 55, 48.

Campell, S and S. Fainstein (eds). 2003. Readings in Planning Theory. London: Blackwell Publishing.

Champion, T and G. Hugo(eds). 2004. New Forms of Urbanization Beyond the Urban-Rural Dichotomy. London: Ashgate Publishing Limited.

Clarke, G. 1995. "Re-appraising the Urban Planning Process as an Instrument for Sustainable Urban Development and Management: A Review" in Mosha, A (ed). 1995. A Reappraisal of the Urban Planning Process. Nairobi: UN-Habitat.

Crossley, M., Chisholm, L. \& Holmes, K. 2005. Educational change and evaluation in Eastern and Southern Africa. Compare: A Journal of Comparative Education, 35, 1-6.

Department of Town Planning, Kenya. 1995. "Towards Participatory Planning for Urban Development" in Mosha, A (ed). 1995. A Reappraisal of the Urban Planning Process. Nairobi: UN-Habitat.

Diaw, K., Nnkya, T. \& Watson, V. 2002. Planning Education in Sub-Saharan Africa: Responding to the Demands of a Changing Context. Planning Practice $\mathcal{E}$ Research, 17, 337-348.

DPU 2004. Living between urban and rural areas, London, Development Planning Unit.

Egbu, A., Antwi, A. \& Olomolaiye, P. 2006. An economic assessment of the institution of land use planning in the cities of sub-Saharan Africa. Wolveharmpton RICS.

El-Shakhs, S. 1997. “Towards Appropriate Urban Development Policy in Emerging MegaCities in Africa", in Rakodi, C (ed). The Urban Challenge in Africa: Growth and Management of Its Large Cities. Tokyo: United Nations University Press.

Goodfellow, T. 2010. The Bastard Child Of Nobody'?: Anti-Planning And The Institutional Crisis In Contemporary Kampala. London: Crisis States Research Centre.

Higgs, P. 2008. Towards an indigenous African educational discourse: a philosophical reflection. International Review of Education / Internationale Zeitschrift $f \tilde{A}^{1 / 4 r}$ Erziehungswissenschaft, 54, 445-458.

Hopkins, L. 2001. Urban Development: The Logic of Making Plans. London: Island Press.

Jain, A. 2003. "Making Planning Responsive to and Compatible with, Reforms", Cities Vol. 20(2):143-145.

James Otieno, J. 2009. Internationalization of Higher Education in Africa: Developments, Emerging Trends, Issues and Policy Implications. Higher Education Policy, 22, 263-281.

Jenkins, P, H. Smith and Y. Wang. 2007. Planning and Housing in the Rapidly Urbanizing World. New York: Routledge.

KCC \& BANK, W. 2000. City Development Strategy; A Situational Analysis. Kampala: KCC.

Kessides, C. 2006. The Urban Transition in Sub Saharan Africa. Washington D.C. :Cities Alliance.

Koojo, C. 2005. Physical Plan Implementation in respect to Urban wetland management. Makerere.

Leibowitz, B., Bozalek, V., Carolissen, R., Nicholls, L., Rohleder, P. \& Swartz, L. Bringing the social into pedagogy: unsafe learning in an uncertain world. Teaching in Higher Education, 15, 123-133.

Loeckx, A, K. Shannon, R. Tuts and H. Schure (eds). 2004. Urban Trialogues. Nairobi: UNHabitat. 
Lotz-Sisitka, H. Education for Sustainable Development and retention: unravelling a research agenda. International Review of Education / Internationale Zeitschrift fÃ $1 / 4 r$ Erziehungswissenschaft, 56, 207-220.

Lwasa, S. 2008. "Planning Innovation in Urban Communities of the Sub Saharan Africa: The Ugandan Case", Department of Geography, Makerere University.

Lwasa, S. \& Kadilo, G. 2010. Confronting the urban challenge in Sub Saharan Africa: Participatory Action Research, institutional capacity and governance in Kampala. Commonwealth International Journal for Local Governance, March 2010.

Lwasa, S. 2006. Informal land markets and residential housing development: processes and Implications for Planning in Kampala. PhD, Makerere.

Lwasa, S. A Geo-Information Approach for Urban Land Use Planning in Kampala. From Pharaohs to Geoinformatics FIG Working Week 2005 and GSDI-8, 2005 Cairo, Egypt April 16-21, 2005. 15.

Lwasa, S. Urban Expansion Processes of Kampala in Uganda: Perspectives on contrasts with cities of developed countries. In: Desherbinin, A., ed. Urban Expansion: The Environmental and Health Dimensions, 2004 Cyberseminar. PopulationEnvironment Research Network (PERN).

Lwasa, S., Laplante, B. \& Larsson, L. 2008. Economic Analysis of health related impacts of environmental burdens in Kasubi Kawaala, Kampala. Kampla: Urban Harvest, Kampala City Council.

Mabogunje, A. 1990. "Urban Planning and the Post Colonial State in Africa: A Research Overview", African Studies Review, Vol. 33(2): 121-203.

Mahavir 2005. Focus on Essential Data: Improving Plan-making by Selective Collection of Geo-information. Global Magazine for Geomatics

Mcgill, R. 1988. Planning for Strategic Performance in Local Government. Longrane Planning, 21, 77-84.

Mosha, A (ed). 1994. A Reappraisal of the Urban Planning Process. Nairobi: UN-Habitat.

Mukwaya, P. 2001. Urban Sprawl and Challenges of Public Transportation Services delivery in Kampala - Uganda. MSc, Norwegian University of Science and Technology.

Mukwaya, P. 2005. Can City Form be harnessed to reduce Transport Energy Use? Solutions to Greenhouse Gas (GHG) Emissions Problems in Kampala City Region. START Fellowships. Kampala.

Ndura, E. 2006. Western Education and African Cultural Identity in the Great Lakes Region of Africa: A Case of Failed Globalization. Peace \& Change, 31, 90-101.

Njoh, A. 1999. Urban Planning, Housing and Spatial Structures in Sub Saharan Africa: Nature, Impact and Development Implications of Exogenous Forces. Florida: King's SOAS Studies in Development Geography.

Njoh, A. 2003. Planning in Contemporary Africa : the State, Town Planning and Society in Cameroon. Ashgate, Aldershot.

Nkurunziza, E. 2008. Understanding informal urban land access processes from a legal pluralist perspective: The case of Kampala, Uganda. Habitat International, 32, 109_ 120. of its large cities., Tokyo and New York: United Nations University Press.

Okpala, D. 1990. "The Roles and Influences of External Assistance in the Planning, Development and Management of African Human Settlement Systems", in Third World Planning Review, Vol 12(3). 
Rakodi, C. 1997 (ed)., 1997. The Urban Challenge in Africa: Growth and Management of Its Large Cities. Tokyo: United Nations University Press.

Rakodi, C. 2001. "Forget Planning, Put Politics First? Priorities for Urban Management in Developing Countries", JAG 3(3):15.

Rakodi, C. \& Lloyd-Jones, T. (eds.) 2002. Urban Livelihoods. A People-Centered Approach to Reducing Poverty, London Earthscan.

Shalaby, A. 2003. "Unsustainable Desert Settlements in Egypt: the Product, the Process and Avenues for Future Research", Urban and Regional Planning. Bonn: Cairo University.

Short, J. 2006. Urban Theory: A Critical Assessment. New York: Palgrave Mac Millan.

Simon, D. 1992. Cities, Capital and Development: African Cities in the World Economy. London: Belhaven Press.

Simpson, F. \& Chapman, M. 1999. Comparison of urban governance and planning policy East looking West. Cities, 16, 353-364.

Smyth, R. 2004. The Roots of Community Development in Colonial Office Policy and Practice in Africa. Social Policy \& Administration, 38, 418-436.

Solo, T, E. Perez and S. Joyce. 1'993. "Constraints in Providing Water and Sanitation Services to the Urban Poor", Wash Technical Report No. 85. Prepared for the Office of Health, Bureau for Research and Development, United States Agency for International Development.

Ssemambo, J. 2000. Planning for the Urban Poor Communities in Rubaga Division, Kampala City. Undergraduate, Makerere.

Taylor, N. 1998. Urban Planning Theory Since 1945. London: Sage Publications.

UN-Habitat 2002. Urbanization by Implosion. Habitat International, 12.

UN-Habitat 2008. The State of African Cities. A framezork for addressing urban challenges in Africa. Nairobi: United Nations Human Settlements Programme.

UN-Habitat, 2006/7. State of the World's Cities 2006/7 The MDGs and Urban Sustainability: 30 Years of Shaping the Habitat Agenda. London: Earthscan.

UN-Habitat. 2008/9. Global Human Settlements Report. Harmonious Cities. London: Earthscan.

UN-Habitat. 2009. Global Human Settlements Report. Planning Sustainable Cities. London: Earthscan.

UNCHS (Habitat). 1999. Reassessment of Urban Planning and Development Regulations in African Cities. Nairobi: UN-Habitat.

Valk, A. V. D. 2002. The Dutch planning experience. Landscape and Urban Planning, 58, 10.

Watson, V. 2002. "The Usefulness of Normative Planning Theories", Planning Theory, Volume 1(1). Sage Publications.

Wekwete, K. and A. Helmsing (eds). 1990. Subnational Planning in Southern and Eastern Africa. London: Avebury Press.

Williams, R. L., Reid, S. J., Myeni, C., Pitt, L., Solarsh, G. \& Williams, R. 1999. Practical skills and valued community outcomes: the next step in community-based education. Medical Education, 33, 730-737.

Yhedgo, M. 1986. "Physical Infrastructure Improvement for Squatter Upgrading in Tanzania", Dar-es-Salaam: Ardhi Institute. 


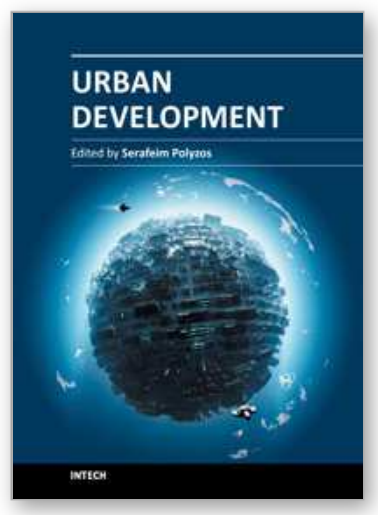

\author{
Urban Development \\ Edited by Dr. Serafeim Polyzos
}

ISBN 978-953-51-0442-1

Hard cover, 296 pages

Publisher InTech

Published online 30, March, 2012

Published in print edition March, 2012

Cities are growing as never before and nowadays, it is estimated that at least $50 \%$ of the world's population lives in urban areas. This trend is expected to continue and simultaneously the problems in urban areas are anticipated to have an increase. Urbanization constitutes a complex process involving problems with social, economic, environmental and spatial dimensions that need appropriate solutions. This book highlights some of these problems and discusses possible solutions in terms of organisation, planning and management. The purpose of the book is to present selected chapters, of great importance for understanding the urban development issues, written by renowned authors in this scientific field. All the chapters have been thoroughly reviewed and they cover some basic aspects concerning urban sustainability, urban sprawl, urban planning, urban environment, housing and land uses. The editor gratefully acknowledges the assistance of Dr Marius Minea in reviewing two chapters.

\title{
How to reference
}

In order to correctly reference this scholarly work, feel free to copy and paste the following:

Shuaib Lwasa and Cecilia Kinuthia-Njenga (2012). Reappraising Urban Planning and Urban Sustainability in East Africa, Urban Development, Dr. Serafeim Polyzos (Ed.), ISBN: 978-953-51-0442-1, InTech, Available from: http://www.intechopen.com/books/urban-development/reappraising-urban-planning-and-urbansustainability-in-east-africa

\section{INTECH}

open science | open minds

\section{InTech Europe}

University Campus STeP Ri

Slavka Krautzeka 83/A

51000 Rijeka, Croatia

Phone: +385 (51) 770447

Fax: +385 (51) 686166

www.intechopen.com

\section{InTech China}

Unit 405, Office Block, Hotel Equatorial Shanghai No.65, Yan An Road (West), Shanghai, 200040, China 中国上海市延安西路65号上海国际贵都大饭店办公楼405单元 Phone: +86-21-62489820

Fax: $+86-21-62489821$ 
(C) 2012 The Author(s). Licensee IntechOpen. This is an open access article distributed under the terms of the Creative Commons Attribution 3.0 License, which permits unrestricted use, distribution, and reproduction in any medium, provided the original work is properly cited. 